Supporting Information for

\title{
Novel Method for the Preparation of Polymeric Hollow Nanospheres Containing Silver Cores with Different Size
}

Daming Cheng, Haibing Xia, Xuedong Zhou, Hardy Sze On, Chan*

Department of Chemistry, National University of Singapore, 3 Science Drive 3, Singapore, 117543 
Scheme S1. Schematic illustration of the preparation of PPy-CS hollow nanospheres.

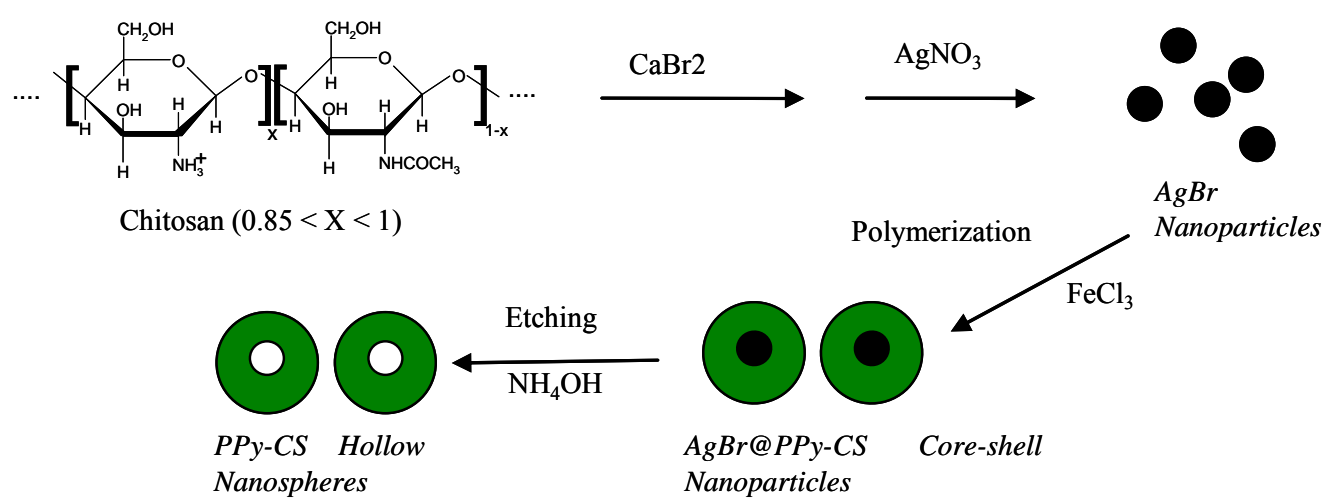

To measure the permeability of the shell, an etching solution containing $\mathrm{NH}_{4} \mathrm{SCN}$ (0.61 wt \%) was added to a series of dispersions which contain AgBr@PPy-CS coreshell nanostructures at various $\mathrm{pH}$ values $(2.2,3.3$, and 6.4$)$. The UV-vis absorption band of $\mathrm{AgBr}$ centered at $310 \mathrm{~nm}$ was monitored over time to detect the transport rate of $-\mathrm{SCN}^{-}$ions through the PPy-CS shell. The intensity of this absorption band decreases as $-\mathrm{SCN}^{-}$ions come through the shell to dissolve $\mathrm{AgBr}$. It shows that decreasing the $\mathrm{pH}$ causes the transport rate to slow down. The fastest transport rate appears at $\mathrm{pH}=6.4$ while the slowest transport rate is observed at $\mathrm{pH}=2.2$.

These results could be rationalized by considering the cationic characteristics of PPyCS shell since both chitosan and polypyrrole are cationic polymers. For PPy-CS hollow nanocube, the main component of the shell is chitosan $(89.6 \%)$. Thus the shell behaves more like chitosan. The structure of a representative poly(aminosaccharide) segment of chitosan is given in Scheme S1. Chitosan is a weak alkaline with a pKa of 6.5. When the $\mathrm{pH}$ of the medium is lower than 6.5 , chitosan carries a positive charge 
along its backbone. Decreasing the $\mathrm{pH}$ causes an increase of $-\mathrm{NH}_{3}{ }^{+}$ions on chitosan molecules. ${ }^{3}$ This brings strong electrostatic attractive force between the positive $\mathrm{NH}_{3}{ }^{+}$ion and the negative $-\mathrm{SCN}^{-}$ion. It would retard the transportation of $-\mathrm{SCN}^{-}$ion through the shell. This accords with the fact that the transport rate at $\mathrm{pH}=3.3$ was faster than that of $\mathrm{pH}=2.2$. As the $\mathrm{pH}$ value of the medium increases, chitosan will be less charged. The electrostatic attraction force becomes less strong which makes $\mathrm{SCN}^{-}$ion easier to go through the shell. This explains why the transport rate at $\mathrm{pH}=$ 6.4 is faster than those of $\mathrm{pH}=2.2$ and 3.3. Thus we are able to control the permeability of the PPy-CS shell by simply adjusting the $\mathrm{pH}$ of the medium.

\section{Experimental Section}

Materials. Pyrrole (99.9\%), Iron(III) chloride $\left(\mathrm{FeCl}_{3}, 99 \%\right)$, Silver nitrate $\left(\mathrm{AgNO}_{3}\right.$, 99+ \%), Calcium bromide $\left(\mathrm{CaBr}_{2}, 99 \%\right)$ and Chitosan (Mw: 300,000 Da, degree of deacetylation: $85 \%$, determined by FT-IR) were purchased from Sigma-Aldrich. Pyrrole was purified by distillation in vacuum before polymerization. Other reagents were used as received without further purification. Water purified with cartridges from Millipore (NANOPure, Barnstead, USA) to a resistivity of $18.0 \mathrm{M} \Omega \cdot \mathrm{cm}$ was used in the preparation of all samples. Precautions were taken to ensure the cleanliness of the distilled water, reagents and the glass vessels used. The presence of traces of silver might subsequently serve as unwanted nucleation centers.

Preparation of PPy-CS Hollow Nanospheres. AgBr nanospheres were prepared first 
according to a well-known method ${ }^{1}$ with necessary modification. $\operatorname{AgNO}_{3}(0.1 \mathrm{~g}, 1$ equiv.) and $\mathrm{CaBr}_{2}(0.07 \mathrm{~g}, 1$ equiv.) were added simultaneously to $20 \mathrm{ml}$ of chitosan solution $\left(1 \mathrm{wt} \%\right.$, in $\left.0.05 \mathrm{M} \mathrm{HNO}_{3}\right)$ to form $\mathrm{AgBr}$ emulsion. Pyrrole $(0.025 \mathrm{ml})$ was then introduced to the emulsion followed by $\mathrm{FeCl}_{3}(0.14 \mathrm{~g})$ to initiate the polymerization. The polymerization was conducted at $2{ }^{\circ} \mathrm{C}$ for $12 \mathrm{~h}$. The product was purified by dialysis using a membrane bag (Spectrum Medical Industries, Inc. Mw cut-off: $3,500 \mathrm{Da}$ ) in $0.05 \mathrm{M} \mathrm{HNO}_{3}$. Finally, the AgBr@PPy-CS core-shell material was obtained by precipitating with acetone and dry in vacuum at $40{ }^{\circ} \mathrm{C}$ for $24 \mathrm{~h}$. The yield of the final product was about $60 \%$.

0.005 g of AgBr@PPy-CS core-shell nanoparticles was first dispersed in $20 \mathrm{ml}$ of distilled water by ultrasonication. The $\mathrm{NH}_{4} \mathrm{SCN}$ solution $(0.61 \%, 3 \mathrm{ml})$ was then added to the dispersion. The reaction was continued for $6 \mathrm{~h}$ at room temperature. After that, the formed $\left[\mathrm{Ag}(\mathrm{SCN})_{2}\right]^{-}$ions were removed by dialysis with a membrane bag (Mw cut-off: 3,500 Da) in water. The PPy-CS hollow nanoparticles was obtained by precipitating in acetone and dry in vacuum at $40{ }^{\circ} \mathrm{C}$ for $24 \mathrm{~h}$.

Preparation of Ag@PPy-CS Core-shell Nanoparticles. 0.005 g of PPy-CS hollow nanosphere was first dispersed in $5 \mathrm{ml}$ of $\mathrm{AgNO}_{3}$ solution (Four different $\mathrm{AgNO}_{3}$ solutions were used in a series of experiments. The concentrations are $3.8 \times 10^{-3} \mathrm{M}$, $5.7 \times 10^{-3} \mathrm{M}, 7.6 \times 10^{-3} \mathrm{M}$, and $9.5 \times 10^{-3} \mathrm{M}$, respectively.) The $\mathrm{pH}$ of the dispersion was adjusted to 6.4 using diluted $\mathrm{NaOH}$ solution $(0.5 \mathrm{M})$. The $\mathrm{pH}$ of the dispersion 
was then adjusted to 2.2 afte it was stirred for one hour. The unwanted Ag ions out of the hollow spheres were then removed by dialysis with a membrane bag (Mw cut-off: 3,500 Da) in water. After that, the mixture was irradiated using a column like, lowpressure mercury lamp (Vilber Lourmat, France, $40 \mathrm{~W}, \lambda=365 \mathrm{~nm}$ ) for $3 \mathrm{~h}$. After reaction, the reaction mixture was purified by centrifuge at $10,000 \mathrm{rpm}$ for $5 \mathrm{~min}$. The resulting sediment was redispersed in deionized water using an ultrasonic bath. This centrifugation-redispersion cycle was repeated three times in order to remove the hollow nanospheres without Ag core.

Characterization. Transmission Electron Microscopy (TEM). TEM images of the samples were recorded on a Philips CM10 electron microscope at an accelerating voltage of $100 \mathrm{kV}$. Samples were first dispersed in water. They were then dried down onto carbon-coated copper grids (150 meshes) for TEM observation. The diameters of the nanoparticles were determined from TEM image by counting 100 nanoparticles.

Ultraviolet-visible Spectroscopy (UV-vis). The optical absorption of the dispersions containing PPy-CS nanospheres or Ag@PPy-CS core-shell nanoparticles was conducted on a Shimadzu (UV1601PC) UV-vis spectrophotometer. Quartz cuvettes with $1 \mathrm{~cm}$ optical path were used as containers.

X-Ray Diffraction (XRD). XRD pattern of the samples were recorded on a Siemens D5005 diffractometer equipped with a $\mathrm{Cu} k \alpha(1.5405 \AA) \mathrm{X}$-ray source. The powders 
were mounted by double-sided adhesive tape on plastic sample holders.

\section{References:}

(1) a) Berry, C. R. In The Theory of the Photographic Process; (Ed. James, T. H.); Macmillan: New York, 1977; Chapter 3; b) Marchetti, A.P.; Hansen, J.C.; Chen, S.; Irving, M.; Baetzold, R.; Sever, B.R. Phys. Rev. B, 2004, 69, 094107.

(2) Hu, Y.; Jiang, X.; Ding, Y.; Ge, H.; Yuan, Y.; Yang, C. Biomaterials, 2002, 23, 3193.

(3) Pa, J. -H.; Yu, T. L. Macromol. Chem. Phys. 2001, 202, 985. 